\title{
Long term donepezil did not delay institutionalisation or progression to disability in patients with Alzheimer's disease
}

AD2000 Collaborative Group. Long-term donepezil treatment in 565 patients with Alzheimer's disease (AD2000): randomised double-blind trial. Lancet 2004;363:2105-15.

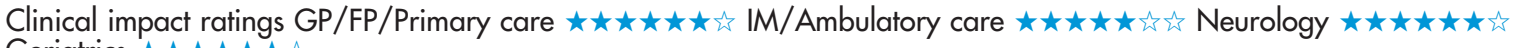

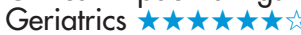

In patients with Alzheimer's disease (AD), does donepezil delay entry to institutional care or progression of disability?

\section{METHODS}

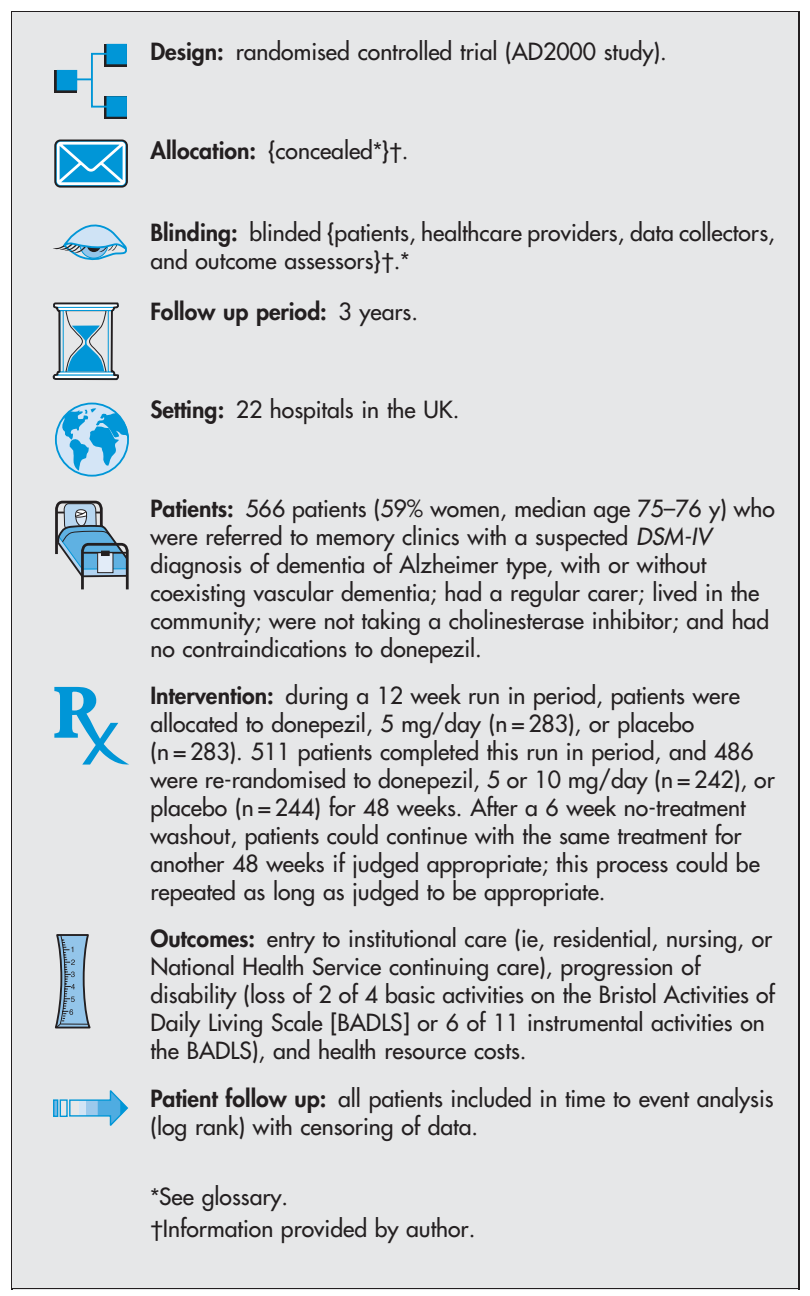

\section{MAIN RESULTS}

Patients in the donepezil and placebo groups did not differ for rates of institutionalisation at 1 year $(9 \% v 14 \%, \mathrm{p}=0.15)$ or 3 years $(42 \% v$

For correspondence: AD2000 Collaborative Group, University of Birmingham Clinical Trials Unit, Birmingham, UK. AD2000@bham.ac.uk Source of funding: NHS Executive R\&D (West Midlands).
$44 \%, p=0.4)$. At a median follow up of 2 years, the relative risk for entering institutional care was 0.97 (95\% CI 0.72 to 1.30 ). The groups did not differ for progression of disability at 1 year ( $13 \% \vee 19 \%$, $\mathrm{p}=0.3)$ or 3 years $(55 \% \vee 53 \%, \mathrm{p}=0.9)$. The relative risk for progression of disability was 1.02 (CI 0.72 to 1.45 ). The mean annual cost per patient resident in the community (for 11 formal health and social services) did not significantly differ between the donepezil and placebo groups $(£ 2842 v £ 2344, \mathrm{p}=0.16)$

\section{CONCLUSION}

In patients with Alzheimer's disease, long term treatment with donepezil did not delay entry to institutional care or progression of disability.

\section{Commentary}

revious trials of donepezil have reported cognitive benefits and varying functional benefits. ${ }^{1} 234$ The AD2000 study also found an initial improvement in cognition but no difference in progression of disability. More novel, they found that donepezil was not cost effective and did not reduce the risk of institutionalisation. Unlike previous studies that have not extended past 1 year, the authors followed up participants for 3 years. Longer duration of follow up is important when examining treatment benefits for Alzheimer's disease, a disorder that results in gradual progressive decline over several years. The study patients were also more representative of older $A D$ patients typically seen in clinical practice in that approximately $50 \%$ had comorbidities. Donepezil is not without adverse effects and should be used cautiously in older patients with comorbidity. Although not statistically significant, the 13 excess deaths in the donepezil group are worrisome.

The study enrolled 566 patients, which is dramatically fewer than the initial target of 3000 . Thus, the study may not have had adequate power to detect differences in several outcomes. The rather broad confidence intervals suggest that donepezil could be associated with a $30-45 \%$ increase or a $28 \%$ decrease in risk of the primary outcomes. Given the lack of evidence of long term benefits and cost effectiveness, the decision to use donepezil requires careful consideration by clinicians, patients, and caregivers.

Jayna M Holroyd-Leduc, MD, FRCPC University of Toronto Toronto, Ontario, Canada

1 Greenberg SM, Tennis MK, Brown LB, et al. Donepezil therapy in clinical practice: a randomized crossover study. Arch Neurol 2000;57:94-9.

2 Burns A, Rossor M, Hecker J, et al. The effects of donepezil in Alzheimer's disease - results from a multinational trial. Dement Geriatr Cogn Disord 1999;10:237-44.

3 Winblad B, Engedal K, Soininen H, et al. A 1-year, randomized, placebocontrolled study of donepezil in patients with mild to moderate $A D$. Neurology 2001;57:489-95.

4 Mohs RC, Doody RS, Morris JC, et al. A 1-year, placebo-controlled preservation of function survival study of donepezil in $A D$ patients. Neurology 2001;57:481-8. 